\title{
CLASSIFICATION OF ANGIOID STREAKS*
}

BY

\author{
R. J. McWILLIAM \\ Victoria Infirmary. Glasgow
}

ANGIOID streaks of the retina were first described by Doyne (1889). They have since been the subject of much controversy. More than 200 cases have been reported in the literature, but histological studies have been few and the changes described have varied. The condition is frequently associated with pseudoxanthoma elasticum, with cardiovascular disease, and with Paget's disease of bone. A similar appearance may also be found after detachments of the choroid, folds of the retina, and other conditions.

The fundus picture consists of reddish or dark brown streaks radiating outwards from the disc, and often seeming to originate from a similar streak running partly or completely round the disc. The constancy of this picture led Collins (1923) to postulate a definite anatomical basis for their distribution and he attributed them to deposits of altered blood pigment lying in the perivascular spaces of the posterior ciliary arteries. However the streaks occur below the retinal vessels and above those of the choroid, so that they must be located either in the deep layers of the retina or in the inner layers of the choroid. Furthermore, the streaks have been seen to be interrupted by areas of choroidal atrophy, an observation which makes it unlikely that they are related to the choroidal vessels (Spicer, 1914; Wildi, 1926).

That the cause of angioid streaks might be breaks in the membrane of Bruch was first suggested by Kofler (1917). His conclusions were drawn solely from clinical observation, and confirmation was not forthcoming until Böck (1938) described such lesions in microscope sections. Böck's report was soon followed by those of Hagedoorn (1939), Klien (1947), Verhoeff (1948), and Winkelman (1948). By courtesy of Sir John McNee, I was able to examine the eyes of a 59-year-old woman in his wards in the Western Infirmary, Glasgow. Angioid streaks were seen. The patient was suffering from essential hypertension and died a few days later from a cerebral haemorrhage. Histological examination of the eyes showed breaks in the lamina vitrea corresponding to the site of one streak (McWilliam, 1951).

There is then agreement that the clinical picture of angioid streaks is associated, in at least a proportion of cases, with a histological picture showing degeneration and gaps in Bruch's membrane. These gaps may not be the only cause, or indeed the cause at all. Ballantyne (1938) and Law (1951) remark that the ophthalmoscopic picture of angioid streaks may not represent one pathological entity. Somewhat similar streaks occur after choroidal detachments, and Law (1938) described plications of the retina with pigmentary debris causing a similar fundus picture.

*Received for publication January 12, 1955. 


\section{Discussion}

Angioid streaks frequently occur in association with four conditions:

(a) pseudoxanthoma elasticum,

(b) cardiovascular disease,

(c) Paget's disease of bone (osteitis deformans),

(d) local changes inside the globe.

Group 1.-In cases associated with pseudoxanthoma elasticum and constituting the Grönblad-Strandberg syndrome, there would appear to be a hereditary weakness of the elastic tissue of the body shown by the skin and eye lesions and widespread vascular defects. Into this group fall those cases of angioid streaks with pseudoxanthoma elasticum and intermittent claudication due to vascular occlusion described by Scheie and Freeman (1946) and by Hibbert (1948). In an examination of the peripheral musculo-elastic arteries in nine cases of the GrönbladStrandberg syndrome, Guenther (1946) found evidence which he considered to indicate degeneration of the elastic tissues of the vessel walls. It is not necessary for the full syndrome to be present in every case, or at any given time.

Group 2.- Streaks may be found in association with cardiovascular disease, most commonly of the arterio-sclerotic, hypertensive type. Often there is other evidence of vascular disease of the retina and choroid, for example, disciform degeneration of the macula. The tendency with increasing age to degeneration of elastic tissue is accelerated by the vascular disease or is produced by the deficient blood supply resulting from the same cause. Degeneration is not confined to the elastic tissue of Bruch's membrane but occurs in the skin, causing senile elastosis. This latter condition is not dissimilar to pseudoxanthoma elasticum and may cause difficulty in histological differentiation. At least five cases of angioid streaks with senile elastosis have been reported in the literature (Scholz, 1941). The association of similar lesions of skin, of Bruch's membrane, and of the elastic tissue of vessel walls in these two groups of case, seems more than coincidental. It would suggest that the local lesions found in the skin and in the fundi have a similar basic aetiology in the two groups.

Group 3.-Cases associated with Paget's disease of bone may also suffer from hypertension, and therefore belong to Group 2. Alternatively, the excess of phosphoric esterase in the blood may lead to calcification and degeneration of a relatively healthy Bruch's membrane. The media of arteries appears to be abnormally prone to calcification in Paget's disease, but true metastatic calcification seems to be uncommon.

To these three types of case in which histological study reveals degeneration of the lamina vitrea, must be added a fourth in which the pathology differs.

Group 4.- In these cases the ophthalmoscopic picture of angioid streaks is caused by pigment accumulations, detachment of the choroid, etc. This group is distinct from the first three, and the angioid streaks may be termed "secondary".

On the available evidence the pathogenesis of the condition in the first three groups of case seems to be as follows. First there is degeneration of the elastic tissue of the lamina vitrea. Winkelman (1948) described early degeneration of the outer elastic layer of this membrane. In his case angioid 
streaks had not been seen during life although the patient suffered from pseudoxanthoma elasticum. Presumably the changes described by him àre the earliest lesions of angioid streaks. This degeneration leads to anatomical defects in the membrane and it becomes less translucent (Hagedoorn, 1939; Klien, 1947; Verhoeff, 1948). The gaps in the membrane show up by contrast. The widespread degeneration is followed by calcification causing intense basophilic staining of the membrane. Ruptures may occur in the membrane without the clinical picture of angioid streaks being present; basophilia of the lamina vitrea occurs in 10 per cent. of senile eyes (Verhoeff and Sisson, 1926; Scholz, 1941). The presence of calcium has been demonstrated by von Kossa's stain and iron compounds have also been found. In general pathology, in many instances calcification is associated with deposit of iron compounds which give a Prussian blue reaction (Muir, 1951). Klien (1947) showed that this iron was not due to old haemorrhage. Ultimately bone formation occurs in the calcified tissues. The evolution of the lesion thus described is in accordance with the degeneration of elastic tissue followed by deposition of calcium and iron and later bone formation which occurs in general pathology.

\section{Conclusions}

From the histology there appear to be two entirely different types of angioid streaks; some cases show degeneration of Bruch's membrane along with systemic changes, and in others the fundus appearance of angioid streaks is secondary to local conditions within the globe, such as retinal folds and choroidal detachments, Bruch's membrane appearing to be intact.

My thanks are due to Sir John McNee for allowing me to refer to one of his cases, and to Professor W. J. B. Riddell for the facilities of the Tennent Institute of Ophthalmology, where the work for this paper was done, and for his help and criticism.

\section{REFERENCES}

Ballantyne, A. J. (1938). Trans. ophthal. Soc. U.K., 58, 207.

BöCK, J. (1938). Z. Augenheilk., 95, 1.

Collins, E. TrEaChER (1923). Trans. ophthal. Soc. U.K., 43, 273.

DOYNE, R. W. (1889). Ibid., 9, 128.

GUENTHER, E. (1946). Acta med. scand., 123, 482.

HaGedOORN, A. (1939). Arch. Ophthal. (Chicago), 21, 746.

HIBBERT, G. (1948). British Journal of Ophthalmology, 32, 478.

KLIEN, B. A. (1947). Amer. J. Ophthal., 30, 955.

KOFLER, A. (1917). Arch. Augenheilk., 82, 134.

LAW, F. W. (1938). Trans. ophthal. Soc. U.K., 58, 191. (1951). Ibid., 71, 248.

MCWILLIAM, R. J. (1951). Ibid., 71, 243.

MUIR, SIR ROBERT (1951). " Text-book of Pathology ", 6th ed. Arnold, London.

SCHEIE, H. G., and FreEMAN, N. E. (1946). Arch. Ophthal. (Chicago), 35, 241.

SCHOLZ, R. O. (1941). Ibid., 26, 677.

SPICER, W. T. HOLMES (1914). Proc. roy. Soc. Med. (Sect. Ophthal.), 8, 33.

VERHOEFF, F. H. (1948). British Journal of Ophthalmology, 32, 531. and Sisson, R. J. (1926). Arch. Ophthal. (Chicago), 55, 125.

WILDI, G. (1926). Klin. Mbl. Augenheilk., 76, 177 (Quoted by Law, 1938).

WINKELMAN, J. E. (1948). Ophthalmologica (Basel), 115, 84. 